www.jmscr.igmpublication.org

Index Copernicus Value: 79.54

ISSN (e)-2347-176x ISSN (p) 2455-0450

crossrefDOI: https://dx.doi.org/10.18535/jmscr/v7i1.177

\title{
Study on awareness of ocular occupational hazards among welders presenting to OPD of tertiary healthcare centre at Bhubaneshwar, Odisha
}

\author{
Authors \\ Dr Nirmala Nagaradagadde ${ }^{1}$, Dr Sri Vaishnavi Mummidi ${ }^{2}$, Dr Zahiruddin Khan ${ }^{3}$ \\ Dr Madhuhati Misra ${ }^{4}$ \\ ${ }^{1}$ Kamineni Academy of Medical Sciences and Research Centre \\ ${ }^{2,3,4}$ Hitech Medical College and Hospital
}

\begin{abstract}
Purpose: The aim was to study the awareness of ocular occupational hazards, safety measures and the use of these measures among the welders.

Materials and Methods: Cross-sectional study of 150 welders. Data was collected using a semi-structured questionnaire with open and close ended questions designed to collect data regarding their sociodemographic profile and work place details.

Observations: Of the 150 welders, majority (74.2\%) are between ages 20 and $35.89 .3 \%$ welders in the sample space had an education below 10th standard. None of them had vocational training and all the skills were acquired while on job. More than half the welders (59.3\%) reported that they were aware of the risk of ocular injuries but only about one-third of the welders (36\%) believed that they need personal protective equipment (PPE) to protect their eyes while the rest feel that the risk of injury, though possible, is very rarethe PPE routinely available aren't appropriate for preventing eye injuries. It is observed that less than a fifth $(18,16.8 \%)$ used any sort of protective equipment. Almost all the welders who use PPE know regarding the risks of ocular injury.

Conclusion: As majority of welders are uneducated, it is important to find ways to create awareness about ocular hazards in welding industry, the reality of the risks and efficacy of PPE at hazard prevention. Delayed presentation to the OPD was due to ignorance of sequelae to injuries about which awareness has to raised. The PPE currently in use are not entirely sufficient to prevent the ocular hazards and hence need a redesign.

Keywords: Occupational hazards, ocular injuries, safety measures, personal protective equipment.
\end{abstract}

\section{Introduction}

Eye related morbidity is the most common occupational hazard reported in several studies. ${ }^{[1,2]}$ and most of the welders suffer from eye related symptoms. Eyes are one of the five sensory organs and eye sight is one of the most cared for function of the human. Despite the protection afforded to the eye by nature, the organ is still exposed to various types of trauma ${ }^{[3]}$. Mostly the anterior segment of the eye bears the brunt of direct and indirect force of the injuries. However, the ciliary body, choroid, retina and vitreous may also be affected. This and rapid industrialisation is the reason that ocular injuries have attained significant importance in ophthalmology. 
We spend most of our life at our place of work and hence the workplace is an important part of our environment. According to World Health Organization (WHO), there are about 250 million cases of work-related injuries per year worldwide. ${ }^{[4]}$ One of the jobs that contribute to these occupational injuries is the welding process, especially in developing countries. ${ }^{[5]}$ The International Standard Classification of Occupations (ISCO) defines welders and flame cutters as welding and cutting metal parts using gas flame, electric arc and other sources of heat to melt and cut, or to melt and fuse metal. ${ }^{[6]}$

It is an established fact that no occupation is without risk of hazard therefore, it is necessary to anticipate, recognise, evaluate and control such hazards. Occupational health aims at the promotion and maintenance of the highest degree of physical, mental and social well-being of workers in all occupations ${ }^{[7]}$. Occupational safety and health (OSH) is not an old science; however, the working conditions and protective measures for workers in general and welders in particular are unsatisfactory.

Hence, the current study assesses the awareness of occupational hazards and protective measures among welders, the factors associated with awareness of the hazards, protective measures, the use of these measures, and the possible relationship between awareness and actual use of PPE (personal protective equipment). This study tries to fill the gap and highlight the need for research of occupational hazards and emphasize on the use of protective measures.

\section{Materials and Methods}

We performed a cross-sectional study during the period of February 2017 to July 2017. A total of 150 cases were included, with a history of intra ocular foreign body sustained while welding, who presented directly or were referred to Hitech Medical College and Hospital, Bhubaneswar. The age group of the patients ranged from 18-57 years. Ethical clearance was obtained from the ethical committee to conduct the study. Consent was obtained from all the subjects who were involved in this study.

During this period of study, a total of 150 cases of intra ocular foreign body injuries while welding were encountered by us. This gives an incidence of $10.1 \%$ of all ophthalmic patients attending the hospital. After a thorough ocular history was taken including the patients' symptoms following the injury, any eye afflictions, previous eye checkups, etc. the patients were subjected to a complete ophthalmic examination which included visual acuity assessment and slit-lamp biomicroscopy. Out of the total number of cases, 22 patients were cases of corneal opacities after foreign body fall and 8 were cases of welders photo keratitis.

Data was collected using a pre-tested semistructured questionnaire with open and close ended questions regarding their sociodemographic variables (age, education, marital status, job status). These variables were divided into categories on the basis of literature review to show their impact on knowledge and use of PPE during analysis. Questions on awareness of hazards of welding, awareness of PPE and use of PPE were structured.

\section{Inclusion criteria}

All the welders above the age of 18, with at least 1 year of working experience were included in the study.

\section{Results}

\section{Socio-demographic profile of welders}

The 150 welders surveyed were aged $27.5+/-6.4$ years and were in between the range of 18 years and 57 years. The majority of them $(106,70.7 \%)$ were between ages 20 and 35. There were no females in the sample group.

Comparison of the categorical variables was done by using the Pearson's Chi Square test for association. A "p" value which was less than 0.05 was considered to be significant.

Table 1 Age profile of study participants $(n=150)$

\begin{tabular}{|l|c|c|c|}
\hline Age & No. of patients & Percentage & P \\
\hline$<30$ & 66 & $44 \%$ & \multirow{2}{*}{0.113} \\
\cline { 1 - 3 } $30-39$ & 54 & $36 \%$ & \\
\cline { 1 - 3 } $40-49$ & 21 & $14 \%$ & \\
\hline $50-59$ & 9 & $6 \%$ & \\
\hline
\end{tabular}


Another socio-demographic factor studied was the literacy level of the 150 welders. 134 (89.3\%) welders in the sample space had an education below 10th standard. However, none of them had vocational training and all the skills were acquired while on job. The $\mathrm{p}$ value of $<0.01$ shows a strongly significant relationship between the education level of the welder and the occurrence ocular injuries.

Table 2 Age profile of study participants $(n=150)$

\begin{tabular}{|l|c|c|c|}
\hline Education & No. of patients & Percentage & P \\
\hline Illiterate & 41 & $27.3 \%$ & \multirow{2}{*}{$<0.01$} \\
\cline { 1 - 3 } Primary & 60 & $40 \%$ & \\
\hline Secondary & 33 & $22 \%$ & \\
\cline { 1 - 3 } High Secondary & 16 & $10.7 \%$ & \\
\cline { 1 - 3 } Graduate \& Above & 0 & $0 \%$ & \\
\hline
\end{tabular}

Table 3 Other associated ocular pathologies

\begin{tabular}{|l|c|c|}
\hline & No. of patients & Percentage \\
\hline Pingecula & 39 & $26 \%$ \\
\hline Astigmatism & 21 & $14 \%$ \\
\hline Cataract & 8 & $5.33 \%$ \\
\hline Flash Burns & 3 & $2 \%$ \\
\hline Pterygium & 19 & $12.7 \%$ \\
\hline None & 70 & $46.7 \%$ \\
\hline
\end{tabular}

Some of the commonly seen eye injuries are arc eye or flash burns to cornea, photo keratosis, diplopia, astigmatism, pingecula, cataract and retinal damage due to exposure to excessive light and ultra violet rays and foreign body injuries to cornea.

\section{Awareness of hazards}

Based on the questionnaire, the awareness of the welder about the serious possibility of ocular hazards and the efficacy of PPE at their prevention was studied. The $p$ value of $<0.01$ here too shows a significant relationship between the awareness level of the welder and the awareness levels about ocular hazards.

Table 4 Awareness levels of participants $(n=150)$

\begin{tabular}{|l|c|c|c|}
\hline Awareness of Ocular Hazards & $\begin{array}{c}\text { No. of } \\
\text { patients }\end{array}$ & $\begin{array}{c}\text { Percentag } \\
\text { e }\end{array}$ & P \\
\hline $\begin{array}{l}\text { Aware of hazards and necessity } \\
\text { of PPE }\end{array}$ & 54 & $36 \%$ & $<0.01$ \\
\cline { 1 - 2 } Aware but PPE not necessary & 35 & $23.3 \%$ & \\
\cline { 1 - 2 } $\begin{array}{l}\text { Not Aware/ Not cognizant of } \\
\text { Hazards }\end{array}$ & 61 & $40.7 \%$ & \\
\hline
\end{tabular}

Another point of note is that even though $36 \%$ of the welders were aware of the necessity of PPE, less than half of them $(26,17.3 \%)$ used any kind of PPE.

\section{Discussion}

The incidence of ocular occupational hazards differs from location to location based on the degree of industrialization and the location of the hospital in relation to industrial area. ${ }^{[8]}$ The incidence of $10.1 \%$ seen in our series is comparable with older reports available in the literature - Zander and Geissler (1864), Weidmann (1888), Praun (1899), Cridland (1929). The recent reports on the subject give an incidence of 109 in non-industrialized areas and $30-50 \%$ in industrial areas (Sorsby - 1964). The relatively low incidence of ocular injuries in our series is due to the fact that some of the patients do not come to the hospital for treatment.

Age turned out to be a non-significant variable. A reason for this may be that while the younger generations have a tendency of carefree and risktaking behaviour the older group may be lethargic or over-confident. However, welders who have been working for a longer duration report more use of PPE, which should reduce the incidence in older age group. However, this needs to be further studied in the future studies.

There were no women who reported with an injury in accordance with many studies conducted. ${ }^{[9]}$ This could be either due to fewer number of women in the industries as women are employed in less dangerous departments or because women are more careful in their work and adhering to the safety measures. This finding was similar to that of other studies by Lambah, Malik and Shukla, who reported that a high number of males were affected as compared to the females varying from $80-90 \%{ }^{[10,11,12]}$.

Level of education had a significant relationship with the occurrence of hazards $(\mathrm{p}<0.01)$, and so did awareness and use of PPE. This agrees with the findings of other such studies. ${ }^{[13]}$ Not only do we know that education and awareness affect ocular hazard frequency, we can postulate that the educated population are more aware and are more likely to follow the safety practices. This is in agreement with Sabitu et $a l^{[14]}$ who also showed 
that awareness increased significantly with an increase in education level.

None of the welders we had come across had any vocational training as compared with the findings of Sabitu et $a l^{[14]}$ where $8.5 \%$ of welders of Kaduna, Nigeria, went to a welding school. Knowledge of hazards, PPE and use of PPE was limited to self-learning on the job. Learning by apprenticeship is common in the welding industry in India; data by Sabitu et $a l^{[14]}$ also show that more than $90 \%$ welders in Kaduna learned welding by apprenticeship. There is no vocational training course or welding school so far for learning welding skills in Bhubaneswar. The welders were not adequately trained or oriented about the hazards and safety measures at work. This might explain a lack of knowledge of the hazards and the protective and first aid measures to be taken in case of an injury.

Though more than half of the welders $(89,59.3 \%)$ were aware of the possibility of ocular hazards, only about a third $(54,36 \%)$ were aware of the necessity of PPE to prevent these from happening. 61 of the 150 welders $(40.7 \%)$ either did not know of the hazards or dismissed the hazard as a minor one or a non-possibility. The study by Isah and Okojie $^{[15]}$ in Benin, Nigeria, showed $91.6 \%$ of welders being aware of one or more hazards of welding, while another study in Kaduna, Nigeria, by Sabitu $\mathrm{K}$ et $a l^{[14]}$ showed $77.9 \%$ of welders aware of one or more hazards of welding.

Use of PPE when compared with the awareness of hazards and PPE at work showed significant relationship similar to other such studies. ${ }^{[16]}$ Thus, the current study shows that when people are aware of hazards and equipments required to protect against them, the tendency to use those equipments increases. Another point of note is that even though $36 \%$ of the welders were aware of the necessity of PPE, less than half of them (26, $17.3 \%$ ) used any kind of PPE. The reasons ranged from financial trouble to a confidence on their expertise. This clearly points to a KAP (knowledge, attitude and practice) gap in this group.
The facility of protective gears was not existing in a major proportion. Of the cases that had the provision, 21 (14\%) wore it 'regularly' and 14 (9.3\%) wore it 'occasionally'. Most $(92.7 \%)$ of the cases were not wearing protective gear at the time of the injury. Eleven persons $(7.3 \%)$ had an injury in spite of wearing protection at the time of the injury. This is probably due to improper glasses which do not cover the side of the eyes through which the flying metal particles fall on the eye. Also, since people other than the welder in the room do not use glasses, the incidence foreign body injuries increases significantly. Further access, awareness and training/orientation of first aid is dismally low, although there are simple and effective ways of limiting accidents and injuries at work site.

\section{Limitations of the study}

The cross-sectional design of the study is one of its major limitations. Results need to be interpreted with caution, in respect to association between hazard exposure and various ailments due to lack of comparison group. We did not analyze the quantification of certain factors like alcohol and tobacco use. To look further into the role of associated factors of injury among welders, longitudinal studies will be required.

\section{Conclusion}

Lack of awareness about severity of risks associated with one's occupation aggravates the worker's health hazards in the work environment. Hence, this study highlights the need for a complete ocular occupational hazard prevention strategy amongst the welders, necessitating preventive education, overall awareness of the hazards and preventive measures alongside devising and ensuring enforcement of safety regulations, as well as preventive education. Further study and analysis is very essential to form an association between the occupational exposure and the various ocular pathologies observed in this study 
There is no principle of Occupational Safety and Health among the welders and their employees. This lacuna needs to be further studied and ventured into so that apt interventions can be planned. OHS needs to be encouraged by the labour organisations in Odisha and should be emphasized by the public health agencies which will make this a significant subject amongst the policy makers.

Implementing the workable behavioral change practices for the prevention of injuries through proper training and adoption of personal protective measures is a vital step. The use of PPE always is a good and safe practice by welders to protect from exposure to dangers and injuries during welding or cutting. Protective devices like goggles and screens are very effective and simple means of preventing injuries to not only the welders but also the people working or standing in the area where the welding is going on. Wearing of safety spectacles at work should be mandated.

\section{References}

1. Norn M, Franck C. Long term changes in the outer part of the eye in welders. Prevalence of spheroid degeneration, pinguecula, pteryguim and cornea cicatrices. Acta Ophthalmol (Copenh) 1991;69:382

2. Isah EC, Okojie OH. Occupational Health Problems of Welders in Benin City, Nigeria. J Med Biomed Res. 2006;5:64-9.

3. Malik S, Gupta A K, Chaudhry S. A study on pattern of ocular injuries in Delhi. Indian J Ophthalmol [serial online] 1968 [cited 2017 Oct 26];16:178-82.

4. A vision for all. Geneva: WHO; 1998. World Health Organization (WHO). The World Health Report 1998-Life in the $21^{\text {st }}$ century; pp. 5-6.

5. Sabitu K, Iliyasu Z, Dauda MM. Awareness of occupational hazards and utilization of safety measures among welders in kaduna metropolis, Northern Nigeria. Ann Afr Med. 2009;8:46-51.
6. International

Labor

Organisation. Updating the International Standard Classifications of occupations.ILO: Department of Statistics; 2008. [Last accessed on 2011 Sept 20].

7. Park K. Park's textbook of preventive and social medicine. 20 ed. Jabalpur, India: Banarasidas Bhanot Publishers; 2007. Chapter 16, Occupational Health; pp 65873.

8. Shukla I M, Verma R N. A clinical study of ocular injuries. Indian J Ophthalmol [serial online] 1979 [cited 2017 Oct 26];27:33-6.

9. Somashekar P B., Arvind H S., A study on industrial eye injuries, Journal of clinical and diagnostic research; 2011: Oct 5(5): 1076-81

10. Lambah P. Adult eye injuries at Wolverhampton Trans Ophthal Sec 1968;88:661-73.

11. Malik SRK, Gupta AK A study on pattern of ocular injuries in Delhi. All Ind Oph Sec 1968;16:178-82.

12. Shukla B. Proceedings of the Seminar on Visual hazards in industries, NSPB, India, 1993;32.

13. Chauhan A, Anand T, Kishore J, Danielsen TE, Ingle GK. Occupational hazard exposure and general health profile of welders in rural Delhi. Indian Journal of Occupational and Environmental Medicine. 2014;18(1):21-26. doi:10.4103/0019-5278.134953.

14. Sabitu K, Iliyasu Z, Dauda MM.

Awareness of occupational hazards and utilization of safety measures among welders in Kaduna Metropolis, Northern Nigeria. Ann Afr Med 2009;8:46-51.

15. Isah EC, Okojie OH. Occupational health problems of welders in Benin City, Nigeria. J Med Biomed Res 2006;5:64-9.

16. Budhathoki SS, Singh SB, Sagtani RA, et al Awareness of occupational hazards and use of safety measures among welders: a 
cross-sectional study from eastern Nepal BMJ Open 2014;4:e004646. doi: 10.1136/bmjopen-2013-004646

17. Norn M, Franck C. Long term changes in the outer part of the eye in welders. Prevalence of spheroid degeneration, pinguecula, pteryguim and cornea cicatrices. Acta Ophthalmol (Copenh) 1991;69:382-6.

18. Kumar SG, Dharanipriya A. Prevalence and pattern of occupational injuries at workplace among welders in coastal south India. Indian Journal of Occupational and Environmental Medicine. 2014;18(3):135139. doi:10.4103/0019-5278.146911. 